\title{
Description of the General Procedure of a Stress Inoculation Program to Cope with the Test Anxiety
}

\author{
Isabel Serrano Pintado', María del Camino Escolar Llamazares ${ }^{2}$ \\ ${ }^{1}$ Department Personalidad, Evaluación y Tratamiento Psicológico, Facultad de Psicología, Universidad de \\ Salamanca, Salamanca, España \\ ${ }^{2}$ Department Personalidad, Evaluación y Tratamiento Psicológico, Facultad de Humanidades y Educación, \\ Universidad de Burgos, Burgos, España \\ Email: serrano@usal.es, cescolar@ubu.es
}

Received 16 April 2014; revised 12 May 2014; accepted 8 June 2014

Copyright (C) 2014 by authors and Scientific Research Publishing Inc.

This work is licensed under the Creative Commons Attribution International License (CC BY).

http://creativecommons.org/licenses/by/4.0/

c) (i) Open Access

\begin{abstract}
We set out the stages in the general procedure of a stress inoculation program for the treatment of test anxiety in university students, with the aim of adapting it to the characteristics of each participant. Research has previously been conducted to that end (Serrano, Delgado, \& Escolar, 2010; Serrano, Escolar, \& Delgado, 2002; Serrano, Escolar, \& Delgado, 2011) on dismantling strategies in a real clinical field. We conclude that there are individual response patterns to test anxiety, so it is therefore necessary to adapt the intervention to the principle variable that is affected in each individual (Escolar \& Serrano, 2012). We do not consider that training in study skills is appropriate, when treating problems of irrational anxiety.
\end{abstract}

Keywords

Stress Inoculation, Irrational Test Anxiety, Worry-Emotionality, Individual Response Patterns

\section{Introduction}

The evaluation anxiety represents a prolific line of research that has generated many areas of psychological intervention (Iruarrizaga \& Salvador, 1999; Miralles \& Hernández, 2012; Miralles \& Sanz, 2011; Ramirez \& Beilock, 2011).

The significant and debilitating effects of tests in modern society on individuals' emotional well-being and cognitive performance (Amutio \& Smith, 2008; Bonaccio, Reeve, \& Winford, 2012; Conley \& Lehman, 2012;

How to cite this paper: Serrano Pintado, I., \& Escolar Llamazares, M. C. (2014). Description of the General Procedure of a Stress Inoculation Program to Cope with the Test Anxiety. Psychology, 5, 956-965. 
Gutiérrez-Calvo, 1996; Miralles \& Hernández, 2012; Miralles \& Sanz, 2011; Nemati \& Habibi, 2012; Piemontesi \& Heredia, 2009; Polo, Hernández, \& Pozo, 1996; Rosário et al., 2008; Spielberger \& Vagg, 1987; Szafranski, Barrera, \& Norton, 2012) have led to the extensive development of "test anxiety" programs, as described by Escolar and Serrano (2012). These treatments have provided adaptive strategies for students with test anxiety to face the exam situation rather than to avoid it, and so prevent a significant decrease in academic achievement (Serrano \& Delgado, 1990; Serrano \& Delgado, 1991; Serrano, Delgado, \& Escolar, 2010; Serrano \& Escolar, 2011; Serrano, Escolar, \& Delgado, 2002; Serrano, Escolar, \& Delgado, 2011).

Moreover, many studies have been completed on the treatment of test anxiety with the objective of demonstrating that one particular treatment is effective at reducing this type of anxiety and/or at improving the cognitive performance of students (Escolar \& Serrano, 2012).

In this direction, Zeidner (2007), considered necessary to set up a program of intervention directed at the control of this type of anxiety and to develop effective therapeutic methods for their treatment, specifically based on studies of efficiency.

Thus, authors such as Furlan, Sánchez, Heredia, Piemontesi and Illbele (2009), Martínez-Monteagudo, Inglés, Cano-Vindel and García-Fernández (2012), Miralles and Hernández (2012), Miralles and Sanz (2011), Onwuegbuzie and Daley (1996), and Zeidner (1998) have all proposed the need to adapt the coping strategy to the type of response that is principally affected in each individual (cognitive and/or emotional), as the same therapeutic procedures may not be successful for all students who suffer from test anxiety (Escolar \& Serrano, 2012). Zeidner (1998) considered that therapeutic interventions and techniques would be effective if they could be adjusted to the needs of different types of students with test anxiety, as each one may be characterized by different problems and concerns. Clearly, a one-size-fits-all program of treatment can never be expected to be equally effective.

Given this situation, the objective of our research (Serrano et al., 2002, 2010, 2011) has been to study the differential efficacy of coping strategies in the reduction of test anxiety, as a function of the variable predominantly affected in the student: the cognitive variable or the emotional variable.

For this end, we adapt the characteristics of each participant to a stress inoculation program (IEA) for the treatment of test anxiety, with dismantling strategies in a real clinical field. These participants were students enrolled in the Salamanca University (Spain). The IEA was designed to develop coping skills. According to Meichenbaum (1985), he combines elements of didactic teaching, socratic discussion, cognitive restructuring, problem solving and relaxation training, behavioral rehearsal imagined, self-recording, self-instruction and reinforcement. It consists of three stages: the first, conceptualization, the second, skill acquisition and practice and the third stage consolidation.

The test anxiety in our work is understood within the conceptual framework of Spielberger (1972a, 1972b), which has also been recently used by authors such as Can, Dereboy and Eskin (2012), Cunha and Paiva (2012), Nemati and Habibi (2012), Piemontesi, Heredia, Furlan, Sanchéz-Rosas and Martínez (2012) and Putwain and Sysmes (2012) among others. We therefore understand that the construct of test anxiety is defined as a specific type of anxiety that reflects the predisposition to manifest anxiety responses in educational situations in which the individuals are or feel evaluated. Moreover, we accept the distinction between irrational anxiety and rational anxiety proposed by Wolpe (1958). That is, we differentiate between students without study skills and without self-control skills over their study behavior, and students who have these skills in their behavioral repertoire and put them into practice. In the first case, we are talking about rational anxiety and in the second case about irrational anxiety. Thus, we considered that the students who suffer test anxiety come under the concept of irrational anxiety. They are in other words, students who know how to study and do so in an acceptable manner but, who feel uneasy in real or imagined situations to do with tests that are present, anticipated or remembered. It is therefore a question of students who, in an exam situation, despite preparing themselves in an acceptable way for the test, experience debilitating fear, as a consequence of which their academic performance is below their optimum level, and students who even display avoidance behaviors (Serrano \& Delgado, 1990; Serrano et al., 2010, 2011). These are clearly students who come under the first type referred to by Naveh-Benjamin (1991) and Naveh-Benjamin, McKeachie \& Lin (1987), in other words, those students with good study skills whose poor performance is related to problems of information recall.

In this paper we present: a) a description of the general procedure of a stress inoculation program to cope with the test anxiety used in the authors' previous research, and b) a summary of main findings that make clear how this test anxiety intervention can be tailored to an individual client's need. 


\section{Stages in the General Procedure}

The general procedure and its different stages detailed in Escolar (2007) are listed below:

\subsection{Selection of Participants Distinguishing between Deterioration in Performance and Poor Study Skills}

A public invitation, over eight academic years, has been addressed to all students at the University of Salamanca who requested assistance with test anxiety problems. They were informed in this public invitation (initial session) that it involved the offer of group treatment, of an approximate duration of 12 - 14 sessions arranged over various months, during which time they would learn strategies and skills to confront test anxiety and to resolve the problems it caused.

They were then administered a general questionnaire on anxiety, specifically, the trait version of the State/ Trait Anxiety Inventory (STAI) (STAI E/R; Spielberger, Gorsuch, \& Lushene, 1970). This inventory has good validity and reliability, Spielberger (1983) reported validity measures from 75 - 85 and measures of test-retest reliability from 73 - 86 (Sapp, 1999).

In addition, they were administered:

-The Test Anxiety Inventory (TAI; Spielberger, 1980), which measures the trait test anxiety responses in its physiological and cognitive manifestations. It has a reliability index, according to the Cronbach's Alpha coefficient, of 0.92 .

-The Test Anxiety Scale (TAS; Sarason, 1978), which measures the trait test anxiety response in its physiological and cognitive contexts. The test-retest reliability index is 0.87 (Wagaman, Cornier, \& Cornier, 1975).

-The Cuestionario de Ansiedad ante los Exámenes [Questionnaire on the assessment of anxiety behaviours in exams] (CAEX) by Valero, 1997 (cited in Valero, 1999), which covers a variety of motor, verbal, cognitive, and physiological responses that usually appear in test anxiety, together with the typology of the most frequent tests. According to the author, the internal consistency of Cronbach's Alpha is 0.92.

-The Inventario de Hábitos de Estudio [Study Habits Inventory] (IHE; Pozar, 1979) evaluates the work and study habits of students on four scales. Scale I: Study Environmental Conditions; Scale II: Planning Study; Scale III: Use of Materials; Scale IV: Assimilation of Contents, and Sincerity Scale (additional scale). The IHE according to the two-halves model has a reliability index of over 0.91 .

This permits us to evaluate anxiety over untreated themes, the trait test anxiety response and study habits in pre-treatment situations.

At the end of this initial session, it was explained that the program targets those students whose academic performance is weakened due to anxiety and not those with poor study behavior (in coherence with our definition of test anxiety).

\subsection{Evaluation Pre-Treatment of Situational Test Anxiety}

We contacted the students during the first term, to inform them that. Thus, immediately after finishing one of the exams judged by them as "the most difficult", we evaluated their state test anxiety, with:

-The Inventory of Test Anxiety (ITA; Osterhouse, 1969), which measures the state test anxiety response, in its physiological and cognitive manifestation. Osterhouse specifically developed it to measure the effects of treatment directed at the reduction of test anxiety. The reliability obtained by the two-halves method was 0.92 (McMillan \& Osterhouse, 1972; Osterhouse, 1972).

-The Cognitive Interference Questionnaire (CIQ; Sarason, 1984), which measures the response of the test anxiety state, in its cognitive manifestation. Specifically, it measures the frequency of adverse and irrelevant thoughts for the task at hand.

-An inventory of general anxiety in its state version, in concrete The State-Trait Anxiety Inventory (STAI E/R; Spielberger et al., 1970).

\subsection{Selection of the Sample}

The two aforementioned evaluation stages permit us to establish the degree of state-trait anxiety levels on topics unrelated to exams, the levels of state-trait test anxiety, and the study habits of each student. The students who were selected had the highest scores in: a) the questionnaire on general anxiety: The State/Trait Anxiety Inven- 
tory (STAI) (STAI E/R; Spielberger et al., 1970) (above the average of 5.50 on the decatype scale); b) the questionnaires on trait test anxiety: The Test Anxiety Inventory (TAI; Spielberger, 1980) (those participants with medium and high scores); and the Test Anxiety Scale (TAS; Sarason, 1978) (those participants with medium and high scores); and c) in particular, the questionnaires on state test anxiety: The Inventory of Test Anxiety (ITA; Osterhouse, 1969) (those participants with medium and high scores) and the Cognitive Interference Questionnaire (CIQ; Sarason, 1984) (those participants with medium and high scores). Moreover, none of the students presented poor study habits evaluated with the Inventario de Hábitos de Estudio (IHE; Pozar, 1979) (participants with scores of normal, good, and excellent on the scale). The results of the Cuestionario de Ansiedad ante Exámenes (CAEX) proposed by Valero, 1997 (cited in Valero, 1999) assisted us in our decision taking (participants with scores over the average score in all the scales). All of this in accordance with our definition of test anxiety construct.

We assessed the scores of the selected participants, under the components of emotionality and worries in the aforementioned questionnaires. Thus, some individuals presented high and average scores for emotionality and high, average and low scores for worry, and others presented high and average scores for worry and high, average and low scores for emotionality. Logically, there were no individuals with low scores for both components. In this context, in accordance with Liebert and Morris (1967), we understand emotionality to be the affective-physiological experience generated by autonomous activation (Serrano et al., 2010).

\subsection{Assignation of Participants to Experimental Groups}

We assigned the 104 participants who had been selected to the three experimental groups by means of simple random sampling. One group, referred to as "Treatment group 1", would receive cognitive training; a second group, referred to as "Treatment group 2", would receive training in relaxation strategies; and the third group, referred to as "Treatment group 3", would receive training in relaxation strategies and cognitive training.

The dismantling strategy that was carried out may be observed in this section. We systematically dismantled specific components of the stress-inoculation program in three types of intervention, with the final objective of adapting it to the characteristics of each patient.

\subsection{Application of the Program}

The program has three stages: educational, practical, and in application.

a) Educational stage. The concept of test anxiety was separately explained to the three treatment groups. Information was also collected on the way in which the problem appeared to each participant, at the three response levels (cognitive, somatic and behavioral). Subsequently, participants were informed about the desired outcome of the treatment, and the procedures in use to arrive at the proposed objectives were explained and justified.

"Treatment group 1" received an explanation of cognitive restructuring and thought stopping (cognitive treatment) as the sole strategies with which to control negative self-verbalizations and in this way, to control the physiological activation linked with them, and in consequence the behavioral response. "Treatment group 2" received relaxation as the sole strategy with which to control the physiological activation of the anxiety response and by doing so, to confront the other two manifestations of anxiety: the cognitive and the behavioral. "Treatment group 3" received two coping strategies: relaxation, with which to control physiological activation and cognitive training with which they could confront negative self-verbalizations, changing them into positive self-verbalizations.

b) Practical stage. During this stage, the participants learnt about and practiced the skills that have been described over fourteen sessions.

b.1. Training in relaxation

Both the participants in "Treatment group 2" and those in "Treatment group 3" received relaxation training over six sessions. This relaxation training was done following the progressive relaxation scheme of Jacobson (1938), but using a very much briefer version than that of Bernstein and Borkovec (1983), developed by the authors.

b.2. Training in domain of Subjective Units of Anxiety (SUAs)

The participants of the three treatment groups were also instructed in the use of the SUA scale. The objective was to evaluate the subjective experience of the level of anxiety before and after carrying out the confrontations in the hierarchical situations and to communicate them. The relaxation level achieved after the practice was also 
assessed in the case of the participants in "Treatment group 2" and in "Treatment group 3". A scale of 0, for completely relaxed, to 100 , extremely tense, was used.

b.3. Training in the control of self-verbalizations

This training was carried out with the participants in "Treatment groups 1-3" over approximately eight sessions. The negative effect of certain sorts of self-verbalizations pronounced before the test situation, and how they could make use of alternative self-verbalizations was explained to them to confront those negative effects. Subsequently, they were invited to identify the negative self-verbalizations that they pronounced when preparing for an exam: before, during and after them.

All of the self-verbalizations were submitted one by one to logical questions in a process of Socratic dialogue, between the members of the group, in order to analyze their validity and utility. Group formulating another alternative self-verbalization/s of a positive and rational, task-oriented nature.

The last step was to train the groups in thought-stopping and in the substitution of self-verbalizations with external subvocal cues and hidden cues

b.4. Construction of hierarchies

A shared hierarchy was established for all participants in each of the treatment groups, of approximately 10 anxiogenic situations hierarchically organized by SUAs (Subjective Units of Anxiety), usually in accordance with the temporal proximity of a test and its subsequent consequences.

c) Application stage. In this stage, coping skills were used, which had been learnt to face the anxiogenic situations of the respective hierarchies in the imagination. One session was dedicated to training the participants from the three treatment groups in the use of the imagination.

The practical guide for the participants of "Treatment group 1" consisted of the presentation of each hierarchical and coping situation through cognitive restructuring and thought stopping.

The guided practice with the participants of "Treatment group 2" consisted in the presentation of each of the hierarchical and coping situations through the relaxation of the anxiety experienced in each of the tests, until the stress had abated.

The guided practice with the participants of "Treatment group 3" consisted in the presentation of each hierarchical and coping situation, through relaxation and thought-stopping, relating to the anxiety experienced in each of the tests, until they had reduced the stress.

When the participants of all the groups were accustomed to mastering the anxiety provoked by those situations in their imagination, they were confronted with real anxiogenic situations relating to tests. In the last session, they were asked for a list showing the dates of the final tests corresponding to the second term, ordered by their degree of difficulty.

\subsection{Post-Treatment Evaluation}

Immediately after starting the final exams in their second term, we once again measured the degree of anxiety that the students experienced through the following questionnaires: The State/Trait Anxiety Inventory (with the trait version) (STAI E/R; Spielberger et al., 1970), the Test Anxiety Inventory (TAI; Spielberger, 1980), the Test Anxiety Scale (TAS; Sarason, 1978) and the Cuestionario de Ansiedad ante Exámenes (CAEX) by Valero, 1997 (cited in Valero, 1999). We also recorded the study habits by means of the Inventario de Hábitos de Estudio (IHE; Pozar, 1979) ${ }^{1}$.

In the same way as we did for the pre-treatment evaluation, we contacted each of the participants immediately after they had completed what they considered one of their most difficult exam, so as to record the degree of anxiety that they experienced. They therefore responded to the state test anxiety questionnaires: The Inventory of Test Anxiety (ITA; Osterhouse, 1969), the Cognitive Interference Questionnaire (CIQ; Sarason, 1984), and the State/Trait Anxiety Inventory (in its state version) (STAI E/R; Spielberger et al., 1970). There was an interval of between six-to-nine days, from the evaluation of the anxiety trait and the evaluation of the component state, for all participants.

Finally, information was collected orally from participants on their mastery of the situations in vivo.

Having completed the research, the results of which may be found in Serrano et al. (2010, 2011), we verified the adjustment of different strategies to the different characteristics of the patients. In particular, we noted that

\footnotetext{
${ }^{1}$ The reason for the post-intervention measurement of study habits was to test whether anxiety control might have some sort of influence on improving study habits.
} 
the individuals classified as "more emotional" in the pre-treatment observations, benefitted mainly from the combined treatment (Treatment group 3: physiological and cognitive treatment). While the subjects classified as "more worried" (suffer more anxiety at a cognitive level) benefitted equally from the three types of intervention. We therefore considered it sufficient to apply one of the treatments in isolation.

\section{Discussion}

We see, in what follows, a reflection of the results of this program, first of all, for more worried individuals, in second place, for more emotional individuals and thirdly, on the advisability or otherwise of using training in study skills in these programs.

With regard to the subjects classified as more worried, we consider that our results are in accordance with those obtained by Morris, Davis and Hutchings (1981), who established that worry-state test anxiety responded well to the majority of treatments (significant reductions were obtained).

So, as the more worried subjects will benefit equally from the three types of intervention, we consider it sufficient to select one of the two individual treatments (Serrano et al., 2002, 2010). In particular, we considered the advantages of the physiological intervention instead of the cognitive one, for various motives: a) because with this intervention, greater improvements were obtained in our studies (Serrano et al., 2002, 2010, 2011) than with the cognitive treatment, and because the physiological treatment is not negative for any of the participants, as happens with the cognitive treatment in participants with high levels of both emotionality and worry; and, b) because of the results obtained by Serrano and Delgado (1991), in which it may be noted that students with high levels of worry can suffer possible interferences of an attentional nature with the cognitive treatment. We may also recall that, in this regard, various researchers have demonstrated that people exposed to stressful situations have difficulty executing complex mental operations that they confront with stress (Gaudry \& Spielberger, 1971). And, on the contrary, the relaxation treatment (Hernández, Pozo, \& Polo, 1994; Spielberger \& Vagg, 1995) applied during the evaluation counteracted the activated state of the individual and reduced subjectively experienced anxiety, as well as stress. In other words, possibly in these more worried participants the physiological treatment in addition to decreasing the physiological response of anxiety acted positively on cognitive manifestation.

As well, some studies (Fletcher \& Spielberger, 1995; Gonzalez, 1995; Parker, Vagg, \& Papsdorf, 1995) suggest that cognitively focused treatments have consistently been more successful than emotionally focused treatments in the reduction of test anxiety and its components of emotionality and worry. However, it is highly relevant to point out that none of the studies took prior account of the intra-individual variability among these students, which is included in our study.

With regard to the subjects classified as more emotional, where we see the need to apply the combined treatment (Serrano et al., 2010, 2011), it may be observed that some authors such as Morris et al. (1981) found no connection between the type of treatment in use and its effectiveness in the emotionality state. However, other authors such as Kaplan, McCordick and Twitchell (1979) found differential effects in the treatments, the cognitive being superior (Morris et al., 1981). On the other hand, Naveh-Benjamin (1991) observed that the treatments directed at reducing emotional reactions during test situations, such as systematic desensitization, reduced the emotionality state of test anxiety, but had less effect on academic performance.

In these studies we can see that data on the emotionality of the test anxiety concept are confusing. We therefore think that we have taken a step forward with this research, in so far as we have shown in our work (Escolar \& Serrano, 2012; Serrano et al., 2002, 2010, 2011; Serrano \& Escolar, 2011) that a complete intervention is needed, both of a physiological and of a cognitive type, for subjects with high emotionality.

Some authors have pointed to the complexity of the affective facet of this construct, for example, Liebert and Morris (1967) and Cassady and Johnson (2002). The latter two considered that emotionality is the subjective knowledge that individuals have on their higher autonomic activation. Others, such as Zeidner (1998), have pointed out that it also involves objective somatic symptoms of physiological activation, such as more subjective expressions of emotional activation and of stress and that it is useful for researchers to differentiate between the real physiological reactions and the person's own personal perception of these reactions. These differences have meant that the term "emotionality" is used to refer to the knowledge and to the interpretation that a person has and makes of physiological activation and of the corporal changes that are experienced in evaluative situations, as against "physiological activation" in itself (Deffenbacher, 1980; Holroyd \& Appel, 1980; Liebert \& Morris, 
1967). Therefore, emotionality implies a considerable degree of cognitive processes; for example, attention that is paid and the interpretations made of affective/physiological activation.

With regard to the pertinence or otherwise of training in study skills, in our experience, the patients who ask for help do so because they either fail to attend exams or because they are unable to pass them. And having received the treatment, they told us that had they managed to sit the exams and that they passed them. Our findings confirm the existence of this irrational anxiety and support the affirmations of authors such as Gonzalez (1995) with regard to the inadvisability of training in study skills, due to the saturation effect on the individual (Serrano et al., 2002, 2010, 2011; Serrano \& Escolar, 2011). This is the reason why in no case did we train patients in study skills in our research. Those who presented rational anxiety were channeled towards training programs in study skills or in self-control of this type of behaviours.

So, we therefore consider that our findings (Serrano et al., 2002, 2010, 2011) are clearly pertinent and decisive for the stage in which an appropriate training is sought for the patient throughout the therapeutic process.

\section{Conclusion}

On the basis of our observations of each individual treated in our studies, we may therefore affirm that individual response patterns do exist in relation to test anxiety. It is therefore necessary to adjust the intervention to the variable that is principally affected in each individual. In other words, we assume that both worry and emotionality can have a negative influence on academic performance. This influence will depend on whether one or another component has affected the student and will be the definitive guide to possible therapeutic interventions (Escolar \& Serrano, 2012; Serrano et al., 2002, 2010, 2011; Serrano \& Escolar, 2011).

Finally, we consider that a careful diagnostic evaluation of the specific weaknesses of students with this type of anxiety is necessary, with a view to further research into test anxiety treatments and their optimization. This requires an evaluation of individual differences in willingness to experience cognitive processes of worry and emotional reactions in test situations and the measurement of attitudes towards study skills and routines. Only then will it be possible to prepare treatment programs in accordance with the specific needs and specific problems of our students.

\section{Acknowledgements}

The authors thank the Psychological Care Unit at the Faculty of Psychology at the University of Salamanca for starting test anxiety treatment groups and allow us to carry them out. Consequently, we would like to thank the ninety-four students that have been the sample for this research for the trust they have placed in our work as a way to alleviate their fears and anxieties.

\section{References}

Amutio, A., \& Smith, J. C. (2008). Stress and Irrational Beliefs in College Students. Ansiedad y Estrés, 14, 211-220.

Bernstein, D. A., \& Borkovec, T. D. (1983). Entrenamiento en relajación progresiva (9th ed.). Bilbao: Desclée de Brouver.

Bonaccio, S., Reeve, C. L., \& Winford, E. C. (2012). Text Anxiety on Cognitive Ability Test Can Result in Differential Predictive Validity of Academic Performance. Personality and Individual Differences, 52, 497-502. http://dx.doi.org/10.1016/j.paid.2011.11.015

Can, P. B., Dereboy, C., \& Eskin, M. (2012). Comparison of the Effectiveness of Cognitive Restructuring and Systematic Desensitization in Reducing High-Stakes Test Anxiety. Turkish Journal of Psychiatry, 23, 9-17.

Cassady, J. C., \& Johnson, R. E. (2002). Cognitive Test Anxiety and Academic Performance. Contemporary Educational Psychology, 27, 270-295. http://dx.doi.org/10.1006/ceps.2001.1094

Conley, K. M., \& Lehman, B. J. (2012). Test Anxiety and Cardiovascular Responses to Daily Academic Stressors. Stress and Health, 28, 41-50. http://dx.doi.org/10.1002/smi.1399

Cunha, M., \& Paiva, M. J. (2012). Text Anxiety in Adolescents: The Role of Self-Criticism and Acceptance and Mindfulness Skills. The Spanish Journal of Psychology, 15, 533-543. http://dx.doi.org/10.5209/rev_SJOP.2012.v15.n2.38864

Deffenbacher, J. L. (1980). Worry and Emotionality in Test Anxiety. In I. G. Sarason (Ed.), Test Anxiety: Theory, Research, and Applications (pp. 111-128). Hillsdale, NJ: Lawrence Erlbaum Associates.

Escolar, M. C. (2007). Eficacia diferencial de estrategias de afrontamiento de la ansiedad ante los exámenes universitarios en función de la variable principalmente afectada. Unpublished Doctoral Thesis, Universidad de Salamanca, Spain. 
Escolar, M. C., \& Serrano, I. (2012). Eficacia de las herramientas cognitivo-conductuales para disminuir la ansiedad en el ámbito educativo. Boletín de la SEAS, 37, 8-21.

Fletcher, T. M., \& Spielberger, C. D. (1995). Comparison of Cognitive Therapy and Rational-Emotive Therapy in the Treatment of Test Anxiety. In C. D. Spielberger, \& P. R. Vagg (Eds.), Test Anxiety: Theory, Assessment, and Treatment (pp. 153-169). Washington DC: Taylor \& Francis.

Furlan, L. A., Sanchez Rosas, J., Heredia, D., Piemontesi, S., \& Illbele, A. (2009). Estrategias de aprendizaje y ansiedad ante los exámenes en estudiantes universitarios. Pensamiento Psicológico, 5, 117-124.

Gaudry, E., \& Spielberger, C. D. (1971). Anxiety and Educational Achievement. New York: Wiley.

Gonzalez, H. P. (1995). Systematic Desensitization, Study Skills Counseling, and Anxiety-Coping Training in the Treatment of Test Anxiety. In C. D. Spielberger, \& P. R. Vagg (Eds.), Test Anxiety: Theory, Assessment, and Treatment (pp. 117132). Washington DC: Taylor \& Francis.

Gutiérrez-Calvo, M. (1996). Ansiedad y deterioro cognitivo: Incidencia en el rendimiento académico. Ansiedad y Estrés, 2 , 173-194.

Hernández, J. M., Pozo, C., \& Polo, A. (1994). Ansiedad ante los exámenes: Un programa para su afrontamiento de forma eficaz. Valencia: Promolibro.

Holroyd, K. A., \& Appel, M. A. (1980). Test Anxiety and Physiological Responding. In I. G. Sarason (Ed.), Test Anxiety: Theory, Research, and Applications (pp. 129-151). Hillsdale, NJ: Lawrence Erlbaum Associates.

Iruarrizaga, I., \& Salvador, M. E. (1999). Intervención cognitivo conductual en los problemas de ansiedad de evaluación. Tratamiento de un caso. Psicología. http://www.psiquiatria.com/revistas/index.php/psicologiacom/article/view/640/

Jacobson, E. (1938). Progressive Relaxation. Chicago, IL: University of Chicago Press.

Kaplan, R. M., McCordick, S. M., \& Twitchell, M. (1979). Is It the Cognitive or the Behavioral Component Which Makes Cognitive-Behavior Modification Effective in Test Anxiety? Journal of Counseling Psychology, 26, 371-377. http://dx.doi.org/10.1037/0022-0167.26.5.371

Liebert, R. M., \& Morris, L. W. (1967). Cognitive and Emotional Components of Test Anxiety: A Distinction and Some Initial Data. Psychological Reports, 20, 975-978. http://dx.doi.org/10.2466/pr0.1967.20.3.975

Martínez-Monteagudo, M. C., Inglés, C. J., Cano-Vindel, A., \& García-Fernández, J. M. (2012). Estado actual de la investigación sobre la teoría tridimensional de la ansiedad de Lang. Ansiedad y Estrés, 18, 201-219.

McMillan, J. R., \& Osterhouse, R. A. (1972). Specific and Generalized Anxiety as Determinants of Outcome with Desensitization of Text Anxiety. Journal of Counseling Psychology, 19, 518-521. http://dx.doi.org/10.1037/h0033583

Meichenbaum, D. (1985). Stress Innoculation Training. Oxford: Pergamon Press Inc.

Miralles, F., \& Hernández, I. (2012). La ansiedad ante los exámenes. Boletín de la SEAS, 36, 9-16.

Miralles, F., \& Sanz, M. C. (2011). Cómo enfrentarse con éxito a exámenes y oposiciones. Madrid: Ediciones Pirámide.

Morris, L. W., Davis, M. A., \& Hutchings, C. H. (1981). Cognitive and Emotional Components of Anxiety: Literature Review and a Revised Worry-Emotionality Scale. Journal of Educational Psychology, 73, 541-555. http://dx.doi.org/10.1037/0022-0663.73.4.541

Naveh-Benjamin, M. (1991). A Comparison of Training Programs Intended for Different Types of Test-Anxious Students: Further Support for an Information-Processing Model. Journal of Educational Psychology, 83, 134-139. http://dx.doi.org/10.1037/0022-0663.83.1.134

Naveh-Benjamin, M., McKeachie, W. J., \& Lin, Y. G. (1987). Two Types of Test-Anxious Students: Support for an Information Processing Model. Journal of Educational Psychology, 79, 131-136. http://dx.doi.org/10.1037/0022-0663.79.2.131

Nemati, A., \& Habibi, P. (2012). The Effect of Practicing Pranayama on Test Anxiety and Test Performance. Indian Journal of Science and Technology, 5, 2645-2650.

Onwuegbuzie, A. J., \& Daley, C. E. (1996). The Relative Contributions of Examination-Taking Coping Strategies and Study Coping Strategies to Test Anxiety: A Concurrent Analysis. Cognitive Therapy and Research, 20, 287-303. http://dx.doi.org/10.1007/BF02229239

Osterhouse, R. A. (1969). A Comparison of Desensitization and Study-Skills Training for the Treatment of Two Kinds of Test-Anxious Students. Unpublished Doctoral Dissertation, Columbus, OH: Ohio State University.

Osterhouse, R. A. (1972). Desensitization and Study-Skills Training as Treatment for Two Types of Test-Anxious Students. Journal of Counseling Psychology, 19, 301-307. http://dx.doi.org/10.1037/h0034177

Parker, J. C. I., Vagg, P. R., \& Papsdorf, J. D. (1995). Systematic Desensitization, Cognitive Coping, and Biofeedback in the Reduction of Test Anxiety. In C. D. Spielberger, \& P. R. Vagg (Eds.), Test Anxiety: Theory, Assessment, and Treatment (pp. 171-182). Washington DC: Taylor \& Francis. 
Piemontesi, S. E., \& Heredia, D. E. (2009). Afrontamiento ante exámenes: Desarrollo de los principales modelos teóricos para su definición y medición. Anales de Psicología, 25, 102-111.

Piemontesi, S., Heredia, D., Furlan, L., Sanchéz-Rosas, J., \& Martínez, M. (2012). Ansiedad ante los exámenes y estilos de afrontamiento ante el estrés académico en estudiantes universitarios. Anales de Psicología, 28, 89-96.

Polo, A., Hernández, J. M., \& Pozo, C. (1996). Evaluación del estrés académico en estudiantes universitarios. Ansiedad y Estrés, 2, 159-172.

Pozar, F. F. (1979). Inventario de hábitos de estudio: IHE. Madrid: TEA.

Putwain, D. W., \& Sysmes, W. (2012). Achievement Goals as Mediators of the Relationship between Competence Beliefs and Test Anxiety. British Journal of Educational Psychology, 82, 207-224. http://dx.doi.org/10.1111/j.2044-8279.2011.02021.x

Ramirez, G., \& Beilock, S. L. (2011). Writing about Testing Worries Boosts Exam Performance in the Classroom. Science, 331, 211-213. http://dx.doi.org/10.1126/science.1199427

Rosário, P., Núñez, J. C., Salgado, A., González-Pienda, J. A., Valle, A., \& Joly, C. (2008). Ansiedad ante los exámenes: Relaciones con variables personales y familiares. Psicothema, 20, 563-570.

Sapp, M. (1999). Test Anxiety. Applied Research, Assessment, and Treatment Interventions. Lanham, MD: University Press of America.

Sarason, I. G. (1978). The Test Anxiety Scale: Concept and Research. In C. D. Spielberger, \& I. G. Sarason (Eds.), Stress and Anxiety (Vol. 5, pp. 193-216). Washington DC: Hemisphere.

Sarason, I. G. (1984). Stress, Anxiety, and Cognitive Interference: Reactions to Test. Journal of Personality and Social Psychology, 46, 929-938. http://dx.doi.org/10.1037/0022-3514.46.4.929

Serrano, I., \& Delgado, J. (1990). Ansiedad ante los exámenes, ¿estado o rasgo? Tratamiento conductual. Studia Paedagogica, 22, 81-93.

Serrano, I., \& Delgado, J. (1991). Estrategias de afrontamiento y ansiedad ante los exámenes. Revista de Psicología General y Aplicada, 44, 447-456.

Serrano, I., \& Escolar, M. C. (2011). Psicopatología de la ansiedad ante los exámenes: Dimensiones y componentes. Escuela y Psicopatología, 2, 135-168.

Serrano, I., Delgado, J., \& Escolar, M. C. (2010). Eficacia diferencial de estrategias de afrontamiento en la reducción de la ansiedad ante los exámenes en función del tipo de variable principalmente afectada. Ansiedad y Estrés, 16, 109-126.

Serrano, I., Escolar, C., \& Delgado, J. (2002). Eficacia diferencial de estrategias de afrontamiento en la reducción de la ansiedad ante los exámenes. Análisis y Modificación de Conducta, 28, 523-550.

Serrano, I., Escolar, M. C., \& Delgado, J. (2011). Eficacia de tres estrategias de afrontamientos en la reducción de la ansiedad ante los exámenes en función del tipo de variable principalmente afectada. In J. M. Román, M. A. Carbonero, \& J. D. Valdivieso (Eds.), Educación, aprendizaje y desarrollo en una sociedad multicultural (pp. 1115-1133). Madrid: Ediciones de la Asociación Nacional de Psicología y Educación.

Spielberger, C. D. (1972a). Anxiety as an Emotional State. In C. D. Spielberger (Ed.), Anxiety: Current Trends in Theory and Research (Vol. 1, pp. 23-49). New York: Academic Press. http://dx.doi.org/10.1016/B978-0-12-657401-2.50009-5

Spielberger, C. D. (1972b). Conceptual and Methodological Issues in Anxiety Research. In C. D. Spielberger (Ed.), Anxiety: Current Trends in Theory and Research (Vol. 2, pp. 481-493). New York: Academic Press. http://dx.doi.org/10.1016/B978-0-12-657402-9.50013-2

Spielberger, C. D. (1980). Test Anxiety Inventory. Palo Alto, CA: Consulting Psychologists Press.

Spielberger, C. D. (1983). Manual for the State-Trait Anxiety Inventory (STAI). Palo Alto, CA: Consulting Psychologists Press.

Spielberger, C. D., \& Vagg, P. R. (1987). The Treatment of Test Anxiety: A Transactional Process Model. In R. Schwarzer, H. M. Van Der Ploeg, \& C. D. Spielberger (Eds.), Advances in Test Anxiety Research (Vol. 5, pp. 179-186). Lisse/Hillsdale, NJ: Swets and Zeitlinger/Erlbaum Associates.

Spielberger, C. D., \& Vagg, P. R. (1995). Test Anxiety: A Transactional Process Model. In C. D. Spielberger, \& P. R. Vagg (Eds.), Test Anxiety: Theory, Assessment and Treatment (pp. 3-14). Washington DC: Taylor \& Francis.

Spielberger, C. D., Gorsuch, R. L., \& Lushene, R. D. (1970). Manual for the State-Trait Anxiety Inventory. Palo Alto, CA: Consulting Psychologists Press.

Szafranski, D. D., Barrera, T. L., \& Norton, P. J. (2012). Test Anxiety Inventory: 30 Years Later. Anxiety, Stress, \& Coping: An International Journal, 25, 667-677. http://dx.doi.org/10.1080/10615806.2012.663490

Valero, L. (1999). Evaluación de ansiedad ante exámenes: Datos de aplicación y fiabilidad de un cuestionario CAEX. Anales de Psicología, 15, 223-231. 
Wagaman, G. L., Cornier, W. H., \& Cornier, L. S. (1975). Cognitive Modification on Test-Anxious Students. Paper Presented at the Meeting of the American Educational Research Association, Washington DC.

Wolpe, J. (1958). Psychotherapy by Reciprocal Inhibition. Stanford, CA: Stanford University Press.

Zeidner, M. (1998). Test Anxiety: The State of the Art. New York: Plenum Press.

Zeidner, M. (2007). Test Anxiety in Educational Contexts: Concepts, Findings, and Future Directions. In P. A. Schutz, \& R. Pekrun (Eds.), Emotion in Education (pp. 165-184). Boston, MA: Elsevier Academic Press.

http://dx.doi.org/10.1016/B978-012372545-5/50011-3 